\title{
Voltammetric Determination of Various Food Azo Dyes Using Different Modified Carbon Paste Electrodes
}

\author{
Rayappa Shrinivas Mahale ${ }^{1 \mathbb{D}}$, Rajendrachari Shashanka ${ }^{2, *}{ }^{\mathbb{D}}$, Shamanth Vasanth ${ }^{1 \mathbb{D}}$, \\ Vinaykumar $\mathbf{R}^{3(\mathbb{D}}$
}

1 School of Mechanical Engineering, REVA University, Bengaluru, Karnataka, India; rayappamahale@gmail.com (R.S.M.); shamanth.v@reva.edu.in (S.V.);

2 Department of Metallurgical and Materials Engineering, BARTIN University, Bartin, Turkey; shashankaic@gmail.com (R.S.);

3 School of Electronics and Communication Engineering, REVA University, Bengaluru, Karnataka, India; vinaykumar.r@reva.edu.in (V.R.);

* Correspondence: shashankaic@gmail.com (R.S.);

Scopus Author ID 55851104900

Received: 16.08.2021; Revised: 22.09.2021; Accepted: 25.09.2021; Published: 3.10.2021

\begin{abstract}
The food industries are developing very fast by improving the taste, odor, appearance of various food products. To do so, they are adding a variety of preservatives, sweeteners, and coloring agents and attracting a huge community of people. Dyes or coloring agents play an important role in enriching food's appearance, quality, and taste. Most used food coloring agents are synthetic azo dyes. They are cheaper than natural dyes, therefore, they are used in huge amounts very frequently. Most of the azo dyes like Amaranth, Tartrazine, Allura Red AC, and Metanil Yellow can cause serious health issues for all the living system, and therefore the use of them in food should be controlled, or the optimum level of these dyes in food and beverages should be measured. Many methods like thin layer chromatography, mass spectroscopy, spectrophotometry, capillary electrophoresis, cyclic voltammetry, high-performance liquid chromatography are used to detect azo dyes in the food. But cyclic voltammetry method is one of the simple, robust, highly selective, accurate, high speed, economical, and highly sensitive methods to determine the presence of azo dyes in foods. The main subject of this review article is the detection of several azo dyes utilizing modified carbon paste electrodes and cyclic voltammetry.
\end{abstract}

Keywords: azo dyes; modified carbon paste electrode; cyclic voltammetry; sensors; food colors.

(c) 2021 by the authors. This article is an open-access article distributed under the terms and conditions of the Creative Commons Attribution (CC BY) license (https://creativecommons.org/licenses/by/4.0/).

\section{Introduction}

Food colorants play an important role in meal selection since they improve the food's stylish appearance, making it more desirable to buyers. However, many colorants become hazardous with prolonged usage, causing health problems. A few examinations have exhibited the relationship of some azo colors with unfavorably susceptible reactions, including asthma and contact hypersensitivity [1-8]. Also, some colorants prompt food bigotry, extreme touchiness, and conduct hyperactivity in youngsters. Cyclic voltammetry and linear sweep voltammetry [9-17] are commonly used along with various nanoparticles modified carbon paste electrodes for detailed studies [18-21]. Colors are grouped into common and engineered. Regular colors are removed from plant and creature sources by actual techniques. Manufactured colors are natural mixes that are combined falsely [2]. Colors are ordered into characteristics and engineered. Common colors are extricated from plant and creature sources 
by actual strategies. Manufactured colors are natural mixes that are integrated misleadingly. Engineered food colors have a few critical points of interest in correlation with normal ones. Azo colors structure the biggest gathering of counterfeit food colors [22-26]. They represent $70 \%$ of all-natural colors delivered on the planet. Tartrazine [25], Sunset Yellow, Azorubine, Allura Red, and Amaranth are the most recognized azo colors in the food sector [2]. However, they possess an electrochemically oxidizable -OH group on a sweet-smelling ring, allowing for anodic voltammetry verification. Much of the time, they are utilized for shading of a dessert shop, jams, confections, jams, frozen yogurt, soda pops, mixed refreshments, and so forth notwithstanding their broad use, a few negative impacts on the human wellbeing were recognized as the aftereffect of various examinations [2]. It is realized that azo colors rot items (for example, fragrant amines) are poisonous and cancer-causing. Furthermore, late distributions support the association of azo colors with human serum egg whites and hemoglobin. As per a few records, made food colorants can cause outrageous energy and hyperactivity in youngsters, particularly when utilized in huge amounts. Additionally, they have the potential to induce infections in people who are particularly susceptible to them, such as asthmatics. The European Food Safety Authority (EFSA) set up the most extreme passable degree of azo tones in drinks and staples. One of the most prevalent and widely used methods for determining diverse analytes is the cyclic voltammetric method [27-30].

Numerous strategies have been utilized for the assurance of different food azo colors. The Electrochemical techniques customarily have discovered wide applications in example examination because of the short investigation time, low force utilization, and economical hardware [3]. Cyclic voltammetry is the most broadly utilized electroanalytical strategy for the subjective data about electrochemical responses [31-34]. Carbon glue cathodes are generally utilized in electroanalysis because of their wide possible window, compound inactivity, ease, and appropriateness for different detecting location applications. Carbon paste electrode (CPE) was broadly utilized on the grounds that because of the minimal effort, getting another reproducible surface. Over the many previous years, CPEs containing different modifiers were generally utilized and applied in the goal of various analytes. CPEs can give a reasonable anode substrate to the planning of a changed cathode.

\section{Determination of Amaranth Dye using Cyclic Voltammetry}

Amaranth (E123. AM) is one of the important azo dyes easily soluble in water and mainly used in beverages, cakes, frozen yogurts, oats, confections, espresso, and in a variety of pharmaceuticals and beauty care products $[4,35-40]$. The first impression of a food's flavor is given through shading. Amaranth is commonly used to give beverages, syrups, and desserts a reddish or caramel tone.

\subsection{Electrochemical behavior of amaranth on screen-printed carbon electrode as a function of} $p H$.

In general, azo dyes can be electrochemically reduced in two processes, causing the signals of distinct dyes to overlap. The use of cyclic voltammetry and Screen-Printed Carbon Electrode (SPCE) can resolve them only at anodic peak currents in the range of 3.2 to 6.8 in the presence of nitric acid and phosphate buffer solutions. The electrochemical oxidation of $\mathrm{AM}$ has been calculated to comprise an electron and one proton. 


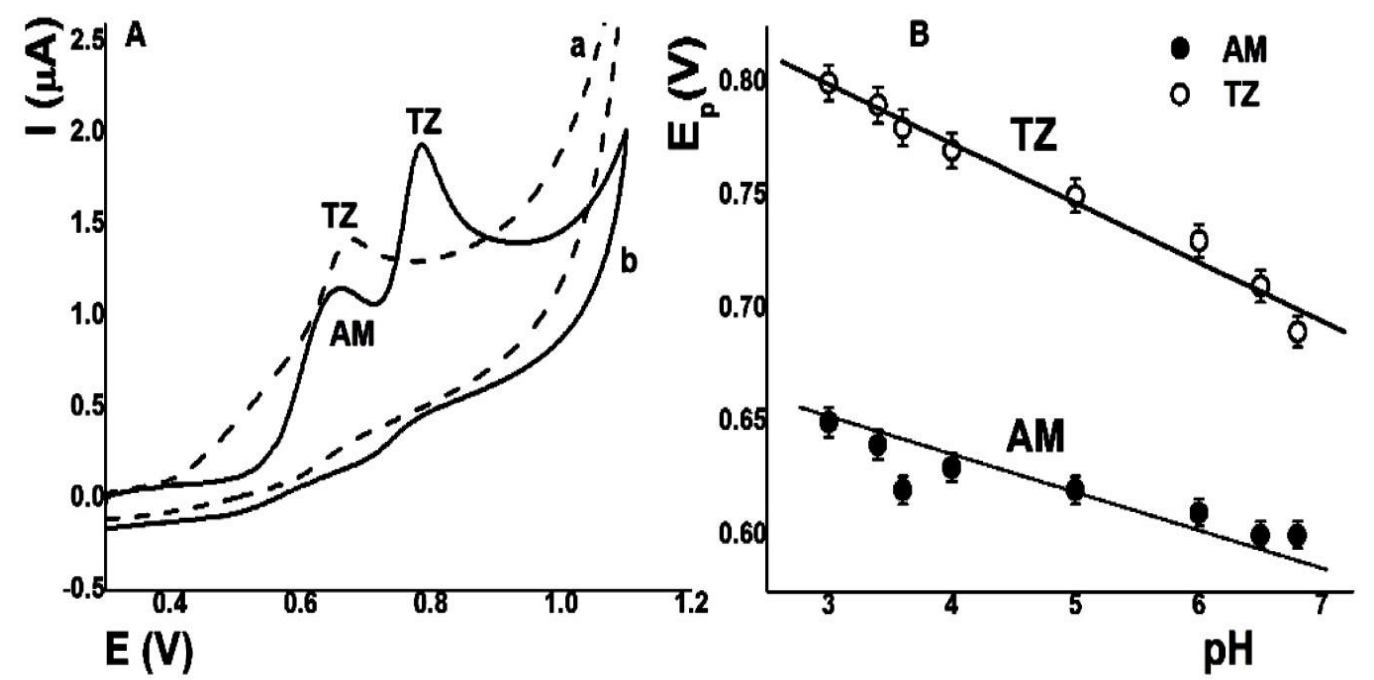

Figure 1. (A) Cyclic voltammograms of Amaranth solution in the presence of nitric acid and phosphoric buffer solution. (B) Effect of $\mathrm{pH}$ on anodic peak potentials of amaranth using screen-printed carbon electrode. Adopted from [4].

The cyclic voltammograms $(\mathrm{CV})$ for amaranth $\left(17.7 \mathrm{~mol} \mathrm{~L}^{-1}\right)$ at $\mathrm{pH} 3.2$ are shown in Figure 1A. (bend a). This picture depicts two all-around defined oxidation tops, one at $0.66 \mathrm{~V}$ (ipa $0.37 \mathrm{~A}$ ) and the other at $0.78 \mathrm{~V}$ (ipa $0.65 \mathrm{~A}$ ), connected to Amaranth oxidation. The contrary output has no decline top, illustrating the irreversible oxidation of these colors. When the $\mathrm{pH}$ was increased, the apex potential shifted in the wrong direction (bend b), showing that protons are involved in AM's electrochemical process. The only evidence of AM at pH 6.8 was a minor articulation $(0.54 \mathrm{~V}$, ipa $0.01 \mu \mathrm{A})$. The flows decreased after increasing the $\mathrm{pH}$ from 3.2 to 6.8. To achieve a delicate and secure method, $\mathrm{pH} 3.2$ was used. Figure 1B shows plots that show the relationship between amaranth's oxidation top possibilities and $\mathrm{pH}$. For amaranth, the inclination obtained for the Epa versus $\mathrm{pH}$ plot is $18 \mathrm{mV}$.

\subsection{Effect of supporting electrolyte (SE).}

The SE lowers the cell's resistance and, as a result, lowers the Ohmic drop effect; meanwhile, it also inhibits the movement of electro-active species towards the electrodes through electrostatic attractions to achieve diffusion-controlled currents [4]. The cyclic voltammograms of AM were observed using SPCE in different SE in the presence of $300 \mu \mathrm{L}$ of nitric acid (curve a), acetic buffer (curve b), or phosphoric buffer (curve c), all of them at a concentration of $0.01 \mathrm{~mol} \mathrm{~L}^{-1}$ (Figure 2). This resulted in strong 2 oxidation peaks. For amaranth, oxidation signals were recorded at $0.66 \mathrm{~V}(0.36 \mu \mathrm{A})$ with nitric corrosive, $0.60 \mathrm{~V}$ $(0.69 \mu \mathrm{A})$ with acetic buffer, and $0.56 \mathrm{~V}(1.34 \mu \mathrm{A})$ with phosphoric buffer. According to these findings, the most remarkable pinnacle flows for amaranth $(1.34 \mu \mathrm{A})$ and the best variation of $\Delta$ Epa occur when the phosphoric buffer is used. The phosphate buffer of $3.2 \mathrm{pH}$ was used to transport all the resultant allot since it provided sufficient affectability and selectivity for determining amaranth. 


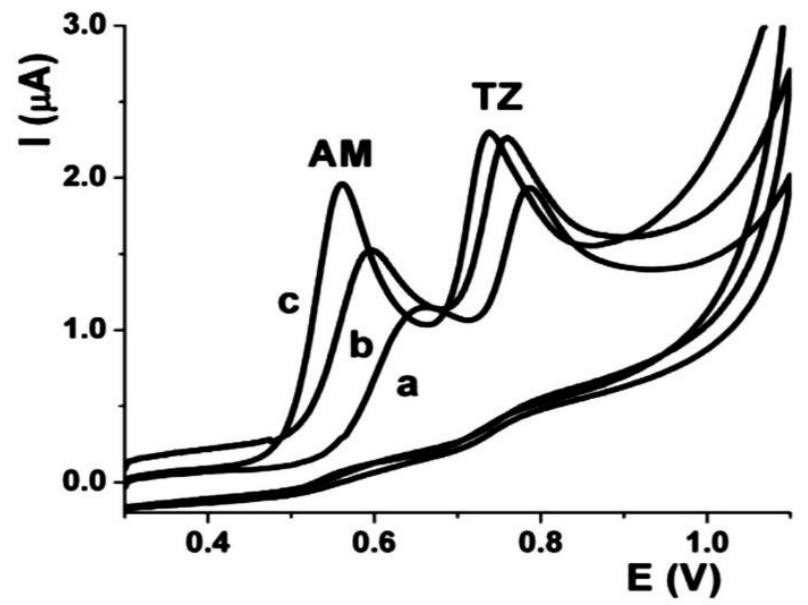

Figure 2. cyclic voltammograms of amaranth $\left(17.7 \mu \mathrm{mol} \mathrm{L}^{-1}\right)$ at $\mathrm{pH} 3.2$; adjusted with nitric acid (curve a), acetate buffer (curve b), and phosphate buffer (curve c). Scan rate $50 \mathrm{~V} \mathrm{~s}^{-1}$. Adopted from [4].

\subsection{The effect of scan rate (v).}

Using SPCE, recognition of the mass transport process was performed to study the effect of sweep rate $(v)$ on anodic peak current for various azo dyes. The relation between Ipa vs. $v$ is as depicted in figure 3. For amaranth, the oxidation peak current increases linearly with $v$ over the range of $10-100 \mathrm{mVs}^{-1}$. This suggests that the electrode reactions are adsorption controlled.

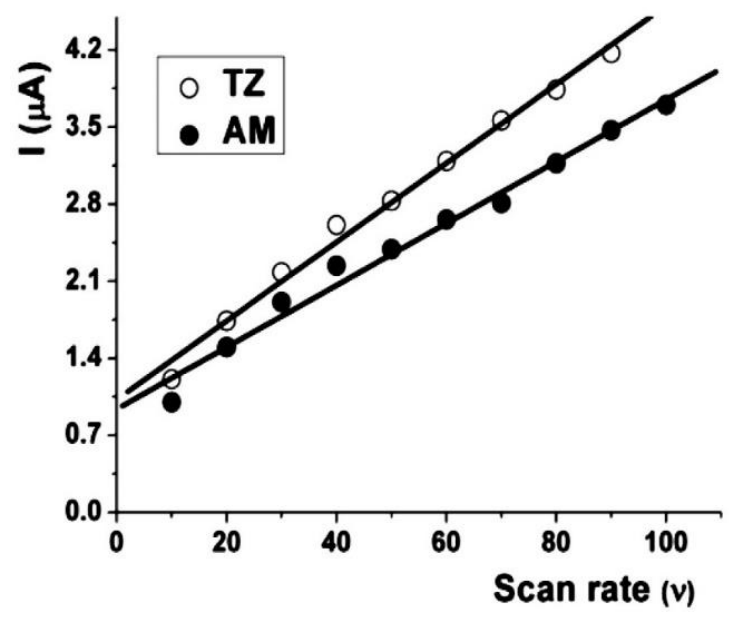

Figure 3. Effects of the scan rate on the anodic peak current of AM and TZ. Adopted from [4].

\subsection{Effect of frequency, step potential, and amplitude.}

Recurrence, step adequacy, and heartbeat plentifulness were the square wave boundaries analyzed. amaranth's anodic pinnacle current grew as all the boundaries grew. In any case, when the recurrence was higher than $10 \mathrm{~Hz}$, the pinnacle of amaranth is expansive, losing a goal. A stage abundance of $10 \mathrm{mV}$ and heartbeat adequacy of $10 \mathrm{mV}$ at a recurrence of $10 \mathrm{~Hz}$ were utilized for additional analyses.

\subsection{Linear range, detection limit, and repeatability of the method.}

Phosphate support pH 3.2 (0.01 mol L), Eads $0.00 \mathrm{~V}$, and smidgens $30 \mathrm{~s}$ were discovered to be ideal scientific conditions. The pinnacle current corresponded to Amaranth clustering over the $0.15-1.20 \mathrm{~mol} \mathrm{~L}^{-1}$ zone under these conditions (Figure 4). 


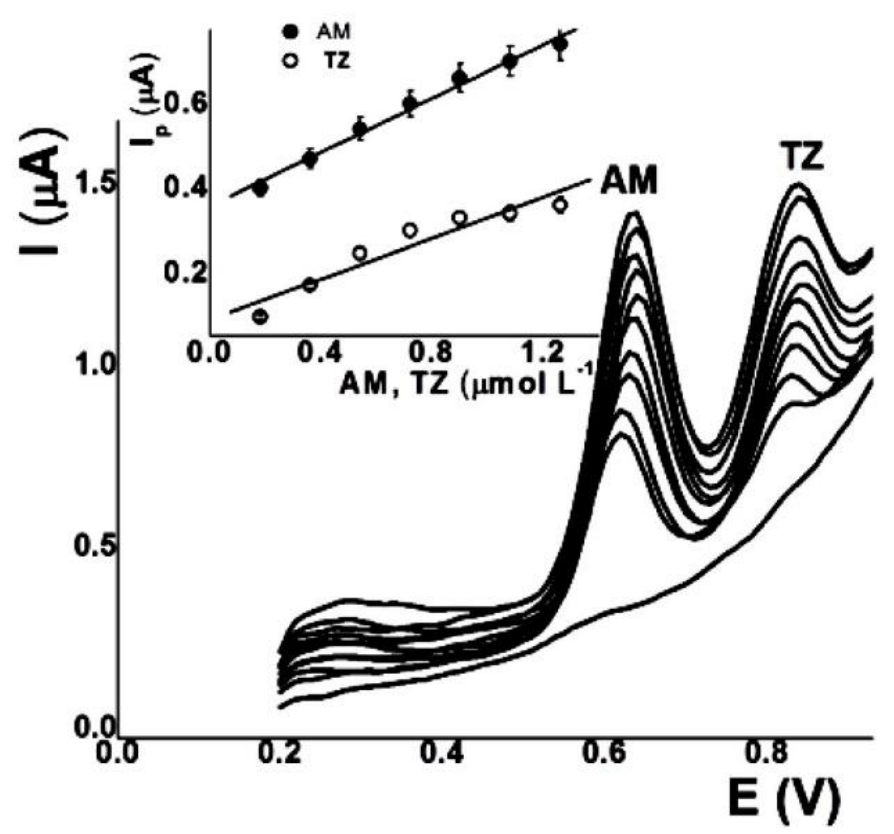

Figure 4. Adsorptive stripping voltammetry and calibration curves for increasing concentrations of AM with SPCE. Adopted from [4].

\section{Cyclic Voltammetric Detection of Tartrazine Dye}

Tartrazine is perhaps the most well-known colorant utilized in a wide scope of nourishments items [41-47]. Today, it is a run-of-the-mill added substance found in types of food, drinks, prescriptions, supplement upgrades, magnificence care items, toiletries, and other non-sustenance things. Colorants are typically allowed up to 200-500 sections per million, with a few exceptions for certain sustenance types with lower limitations [5]. Tartrazine usually causes hazardous side effects and is associated with leading problems as frequently as feasible.

\subsection{Fabrication of carbon paste electrode.}

The bare carbon paste electrode (BCPE) was made by mixing graphite powder (150 mesh) and silicone oil in a 70:30 percent weight-to-weight ratio [18-21]. The glue was then packed into the depression of a scratch-built cathode that had been streamlined on gauging paper.

\subsection{Preparation of the poly glycine modified carbon paste electrode (PGMCPE).}

The BCPE was electrochemically activated 10 times by cycling the potential sweeps in the range of 500 to $1800 \mathrm{mV}$ in PBS. The modified terminal was made in $1 \mathrm{mM}$ glycine under the same circumstances as the cathode actuation approach. The corrected terminal was flushed with purified water after electropolymerization.

\subsection{Results and discussions.}

According to Manjunatha [5], cyclic voltammograms were estimated for cathodes flooded in $\mathrm{pH} 7 \mathrm{PBS}$ containing $\mathrm{Tz}\left(1 \times 10^{-4} \mathrm{M}\right)$. Tz demonstrated a fair electrochemical reaction, equivalent to $\mathrm{BCPE}$. Tz's oxidation potential and current were $883 \mathrm{mV}$ and $11.32 \mathrm{~mA}$ at BCPE, and $918 \mathrm{mV}$ and $30.46 \mathrm{~mA}$ at PGMCPE, respectively. These findings suggest that PGMCPE can accelerate the movement of Tz electrons. Differential pulse voltammetric tests 
were also carried out by Manjunatha [5]. Tz's electrochemistry on the BCPE revealed a little oxidation peak at around $870 \mathrm{mV}$. In any instance, a sharp peak at $911 \mathrm{mV}$ was observed at the PGMCPE, indicating that the PGMCPE showed significant electrocatalytic action toward Tz oxidation.

\section{Investigation of Metanil Yellow Dye using Cyclic Voltammetry}

Synthetic colors are more common in food products nowadays, which affect human health. The banned food color Metanil yellow is a known mutagen and a class II toxin according to the World Health Organization [6]. The development of cancer and the degradation of stomach mucus have been connected to this color. Nanomaterial-based electrochemical sensors are a unique detecting technology that may be used in various monitoring and analytical applications.

\subsection{Differential pulse voltammetry (DPV) of Metanil Yellow (MY) and Fast Green (FCF).}

The DPV is one of the important electrochemical methods generally used to detect the analytes with high resolution. Following that, in the current study, DPV was used to record the voltammetric marks of MY and FCF at bare and modified electrodes at a rate of $5 \mathrm{mV} / \mathrm{s}$ at a potential of 0 to $1.2 \mathrm{~V}$ and maintaining the amplitude and width respectively at $50 \mathrm{mV}$ and 70 ms. The figure reported by Shah [6] depicts that Metanil yellow and FCF oxidize at 0.58 and $0.84 \mathrm{~V}$, individually.

Both analytes were evaluated simultaneously after ascertaining the state of the oxidation signals of each MY and FCF. Shah [6] describes the voltammetric reaction of MY and FCF in conjunction. These findings are in good agreement with the EIS findings as reported by Shah in his publication [6]. The component of calixarene and silver nanoparticles can be thought of as a stepping stone that allows electrons to pass from the transducer to the analytes. Due to this, the modifier will attract electrons from the oxidizable entity because of the positive potential being applied via a potentiostat, and so the modifier acts as an extension between the electron-giving entities of the analytes and the acceptor anode. This collaboration between the modifier and the cooler improves the voltammetric response by upgrading the signs of the colors at the modified GCE by encouraging host-guest associations that lead to a larger grouping of the colors near the cathode area.

\subsection{Cyclic voltammetry.}

By varying the scan rate from 25 to $250 \mathrm{mV} / \mathrm{s}$ the voltammetric behavior of MY and FCF was recorded using calix8/Au NPs/GCE. The resulting voltammograms depicted the diffusion-controlled electrochemical processes. As per the published reports, if the slope of the $\log$ of peak current and a $\log$ of scan rate is equal to 1 , the electron transfer mechanism is adsorption controlled. If the same is less than 1 then it is a diffusion-controlled mechanism [9, 18]. During the investigation of condition optimization (effect of supporting electrolyte, $\mathrm{pH}$, and accumulation time), Shah [6] reported that the electrolyte can influence the peak current and shape. He also reported that the increased accumulation time could lead to the intensification of peaks. He has also found that 70 seconds of accumulation time results in the highest peak current and reaches saturation; therefore, no further increase in peak current occurs. 


\section{Electrochemical Determination of Allura Red AC Dye Using Cyclic Voltammetry}

The crimson tone of Allura Red AC is widely used to shade dessert stores, alcoholic beverages, and non-mixed beverages [48]. Despite a lack of clear information on the hazards of azo colors [49, 50], recent studies reveal that the increased use of azo dyes can cause hyperactivity in youngsters and cancer and mutation.

\subsection{Preparation of a carbon paste electrode modified with cetylpyridinium chloride.}

The 0.01 M Allura Red AC solution was prepared using distilled water. The preparation of bare and cetylpyridinium chloride modified carbon paste electrodes were explained by Pliuta et al. [7] in their previous publication.

\subsection{Determination of Allura Red AS in jelly sweets.}

The laboratory mill was used to grind the jelly sweets containing the Allura red dye. Weighed exactly one gram of the ground jelly and dissolved in $100 \mathrm{ml}$ of distilled water. An aliquot of the sample was taken in a $25 \mathrm{ml}$ standard flask and adjusted to the mark with BrittonRobinson buffer of $\mathrm{pH}$ 2. A known quantity of the sample solution was added to the electrochemical cell, and a potential of $300 \mathrm{mV}$ was maintained for 300 seconds, followed by the potential sweep with a scan rate of $250 \mathrm{mV} / \mathrm{s}$ from $0 \mathrm{mV}$ to $1100 \mathrm{mV}$.

5.3. The electrochemical behavior of Allura Red AC using cetylpyridinium chloride modified carbon paste electrode.

Pliuta et al. [7] used cyclic voltammetry to further investigate the electrochemical behavior of the dye using bare and modified electrodes. They reported that the oxidation current increased when they used cetylpyridinium chloride modified carbon paste electrode; meanwhile, the oxidation peak potential shifted towards the cathode and attained $950 \mathrm{mV}$. The oxidation peak current in these modified electrodes is less than the bare electrode due to the blocking of silica gel. The voltammograms of such electrodes show only one peak indicating the irreversibility of the oxidation of the azo dye [7].

\section{Conclusions}

We have reviewed the cyclic redox behavior of various synthetic dyes and their kinetic studies. Nowadays, most food companies are using these synthetic azo dyes, which are unhealthy and cause many diseases. Therefore, determining these dyes in food is very important and can be carried out using cyclic voltammetry. It is one of the sophisticated methods used to sense the presence of azo dyes. Various researchers have reported the selectivity, sensitivity, robustness, and efficiency of azo dyes' and the efficiency of azo dyes' electrochemical sensing using cyclic voltammetry. The various modified carbon paste electrodes, especially nanomaterials and surfactant-based electrodes, are popular and widely used to detect the Amaranth, Allura Red AC, and Mentil Yellow dyes.

\section{Funding}

This research did not receive any specific grant from funding agencies in the public, commercial, or not-for-profit sectors. 


\section{Acknowledgments}

The authors declare no acknowledgments.

\section{Conflicts of Interest}

\section{The authors declare that they have no known competing financial interests or personal relationships that could have influenced the work reported in this paper.}

\section{References}

1. Sierra-Rosales, P.; Toledo-Neira, C.; Squella, J.A. Electrochemical determination of food colorants in soft drinks using MWCNT-modified GCEs. Sensors and Actuators B: Chemical 2017, 240, 1257-1264, https://doi.org/10.1016/j.snb.2016.08.135.

2. Lipskikh, O.I.; Korotkova, E.I.; Khristunova, Y.P.; Barek, J.; Kratochvil, B. Sensors for voltammetric determination of food azo dyes - A critical review. Electrochimica Acta 2018, 260, 974-985, https://doi.org/10.1016/j.electacta.2017.12.027.

3. Raril, C.; Manjunatha, J.G.; Tigari, G.; Hareesha, N. Fabrication of the Tartrazine Voltammetric Sensor based on Surfactant Modified Carbon Paste Electrode. Open Access Journal of Chemistry 2018, 2, 21-26.

4. Perdomo, Y.; Arancibia, V.; García-Beltrán, O.; Nagles, E. Adsorptive Stripping Voltammetric Determination of Amaranth and Tartrazine in Drinks and Gelatins Using a Screen-Printed Carbon Electrode. Sensors 2017, 17, 2-10, https://doi.org/10.3390/s17112665.

5. Manjunatha, J.G. A novel voltammetric method for the enhanced detection of the food additive tartrazine using an electrochemical sensor. Heliyon 2018, 4, 1-14, https://doi.org/10.1016/j.heliyon.2018.e00986.

6. Shah, A. A Novel Electrochemical Nanosensor for the Simultaneous Sensing of Two Toxic Food Dyes. ACS Omega 2020, 5, 6187-6193, https://doi.org/10.1021/acsomega.0c00354.

7. Pliuta, K.; Chebotarev, A.; Pliuta, A.; Snigur, D. Voltammetric Determination of Allura Red AC onto Carbone-paste Electrode Modified by Silica with Embedded Cetylpyridinium Chloride. Electroanalysis 2021, 33, 987-992, https://doi.org/10.1002/elan.202060367.

8. Tvorynska, S.; Josypčuk, B.; Barek, J.; Dubenska, L. Electrochemical Behavior and Sensitive Methods of the Voltammetric Determination of Food Azo Dyes Amaranth and Allura Red AC on Amalgam Electrodes. Food Analytical Methods 2019, 12, 409-421, https://doi.org/10.1007/s12161-018-1372-1

9. Shashanka, R.; Kumara Swamy, B.E. Simultaneous electro-generation and electro-deposition of copper oxide nanoparticles on glassy carbon electrode and its sensor application. SN Applied Sciences 2020, 2, 1-10, https://doi.org/10.1007/s42452-020-2785-1.

10. Shashanka, R. Investigation of Electrochemical Pitting Corrosion by Linear Sweep Voltammetry: A Fast and Robust Approach. Intechopen 2018, 1-14, https://doi.org/10.5772/intechopen.80980.

11. Shashanka, R.; Chaira, D.; Swamy, BEK. Effect of $\mathrm{Y}_{2} \mathrm{O}_{3}$ Nanoparticles on Corrosion Study of Spark Plasma Sintered Duplex and Ferritic Stainless-Steel Samples by Linear Sweep Voltammetric Method. Arch. Metall. Mater 2018, 749-763, https://doi.org/10.24425/122401.

12. Monnappa, A.B.; Manjunatha, J.G.; Bhatt, A.S.; Malini, K. Sodium Dodecyl Sulfate Modified Carbon Nano Tube Paste Electrode for Sensitive Cyclic Voltammetry Determination of Isatin. Adv Pharm Bull 2021, 11, 111-119, https://doi.org/10.34172/apb.2021.012.

13. Souza, E.S.D.; amp; rsquo; Manjunatha, J.G.; Raril, C.; Tigari, G.; Pushpanjali, P.A. Polymer Modified Carbon Paste Electrode as a Sensitive Sensor for the Electrochemical Determination of Riboflavin and Its Application in Pharmaceutical and Biological Samples. Analytical and Bioanalytical Chemistry Research 2020, 7, 461-472, https://dx.doi.org/10.22036/abcr.2020.214882.1445.

14. Charithra, M.M.; Manjunatha, J.G. Fabrication of Poly (Evans Blue) Modified Graphite Paste Electrode as an Electrochemical sensor for Sensitive and Instant Riboflavin Detection. Moroccan Journal of Chemistry 2021, 7-17, https://doi.org/10.48317/IMIST.PRSM/morjchem-v9i1.18239.

15. Monnappa, A.B.; Manjunatha, J.G.; Bhatt, A.S. Design of a Sensitive and Selective Voltammetric Sensor Based on a Cationic Surfactant-Modified Carbon Paste Electrode for the Determination of Alloxan. ACS Omega 2020, 5, 23481-23490, https://doi.org/10.1021/acsomega.0c03517.

16. Manjunatha Charithra, M.; Manjunatha, J.G. Electrochemical Sensing of Paracetamol Using Electropolymerised and Sodium Lauryl Sulfate Modified Carbon Nanotube Paste Electrode. ChemistrySelect 2020, 5, 9323-9329, https://doi.org/10.1002/slct.202002626.

17. Prinith, N.S.; Manjunatha, J.G. Polymethionine modified carbon nanotube sensor for sensitive and selective determination of L-tryptophan. Journal of Electrochemical Science and Engineering 2020, 10, 305-315, https://doi.org/10.5599/jese.774. 
18. Raril, C.; Manjunatha, J.G.; Tigari, G. Low-cost voltammetric sensor based on an anionic surfactant modified carbon nanocomposite material for the rapid determination of curcumin in natural food supplement. Instrumentation Science \& Technology 2020, 48, 561-582, https://doi.org/10.1080/10739149.2020.1756317.

19. Raril, C.; Manjunatha, J.G. A simple approach for the electrochemical determination of vanillin at ionic surfactant modified graphene paste electrode. Microchemical Journal 2020, 154, 1-7, https://doi.org/10.1016/j.microc.2019.104575.

20. Charithra, M.M.; Manjunatha, J.G. Poly (1-Proline) modified carbon paste electrode as the voltammetric sensor for the detection of Estriol and its simultaneous determination with Folic and Ascorbic acid. Materials Science for Energy Technologies 2019, 2, 365-371, https://doi.org/10.1016/j.mset.2019.05.002.

21. Tigari, G.; Manjunatha, J.G. Electrochemical Preparation of Poly(arginine)-Modified Carbon Nanotube Paste Electrode and its Application for the Determination of Pyridoxine in the Presence of Riboflavin: An Electroanalytical Approach. Journal of Analysis and Testing 2019, 3, 331-340, https://doi.org/10.1007/s41664-019-00116-w.

22. Pushpanjali, P.A.; Manjunatha, J.G. Electroanalysis of sodium alizarin sulfonate at surfactant modified carbon nanotube paste electrode: a cyclic voltammetric study. J Mater Environ Sci 2019, 10, 939-947.

23. Balliamada Monnappa, A.; Manjunatha, J.G.; Bhatt, A.S.; Chenthattil, R.; Pemmatte Ananda, P. Electrochemical Sensor for the Determination of Alizarin Red-S at Non-ionic Surfactant Modified Carbon Nanotube Paste Electrode. Physical Chemistry Research 2019, 7, 523-533, https://dx.doi.org/10.22036/pcr.2019.185875.1636.

24. Raril, C.; Manjunatha, J.G. A sensitive and selective procedure for the voltammetric determination of brilliant indigo and acid yellow 23 at surfactant modified graphene paste electrode. J. Mater. Environ. Sci 2019, 10, 510-519.

25. Manjunatha, J.G. A novel voltammetric method for the enhanced detection of the food additive tartrazine using an electrochemical sensor. Heliyon 2018, 4, 1-14, https://doi.org/10.1016/j.heliyon.2018.e00986.

26. Raril, C.; Manjunatha, J.G. Carbon Nanotube Paste Electrode for the Determination of Some Neurotransmitters: A Cyclic Voltammetric Study. Mod Chem Appl 2018, 6, 1-8, https://doi.org/10.4172/2329-6798.1000263.

27. Shrinivas Mahale, R.; Shamanth, V.; Sharath, P.C.; Shashanka, R.; Hemanth, K. A review on spark plasma sintering of duplex stainless steels. Materials Today: Proceedings 2021, 45, 138-144, https://doi.org/10.1016/j.matpr.2020.10.357.

28. Shashanka, R. Investigation of optical and thermal properties of $\mathrm{CuO}$ and $\mathrm{ZnO}$ nanoparticles prepared by Crocus Sativus (Saffron) flower extract. Journal of the Iranian Chemical Society 2021, 18, 415-427, https://doi.org/10.1007/s13738-020-02037-3.

29. Shashanka, R.; Esgin, H.; Yilmaz, V.M.; Caglar, Y. Fabrication and characterization of green synthesized $\mathrm{ZnO}$ nanoparticle based dye-sensitized solar cells. Journal of Science: Advanced Materials and Devices 2020, 5, 185-191, https://doi.org/10.1016/j.jsamd.2020.04.005.

30. Rajendrachari, S.; Be, K. Biosynthesis of Silver Nanoparticles Using Leaves of Acacia Melanoxylon and their Application as Dopamine and Hydrogen Peroxide Sensors. Physical Chemistry Research 2020, 8, 1-18, http://dx.doi.org/10.22036/pcr.2019.205211.1688.

31. Shashanka, R.; Orhan, U.; Chaira, D. Synthesis of nano-structured duplex and ferritic stainless-steel powders by dry milling and its comparison with wet milling. Arch. Metall. Mater 2020, 65, 5-14, http://dx.doi.org/10.24425/amm.2019.131091.

32. Rajendrachari, S. Effect of sintering temperature on the pitting corrosion of ball milled duplex stainless steel by using linear sweep voltammetry. Analytical and Bioanalytical Electrochemistry 2018, 10, 349-361.

33. Shashanka, R.; Chaira D.; Swamy, BEK. Electrochemical investigation of duplex stainless steel at carbon paste electrode and its application to the detection of dopamine, ascorbic and uric acid. International Journal of Scientific and Engineering Research 2015, 6, 1863-1871.

34. Shashanka, R.; Chaira, D.; Swamy, B.E.K. Electrocatalytic Response of Duplex and Yittria Dispersed Duplex Stainless Steel Modified Carbon Paste Electrode in Detecting Folic Acid Using Cyclic Voltammetry. International Journal of Electrochemical Science 2015, 10, 5586-5598.

35. Bafana, A.; Devi, S.S.; Chakrabarti, T. Azo dyes: past, present and the future. Environmental Reviews 2011, 19, 350-371, https://doi.org/10.1139/a11-018.

36. Chung, K.-T. Azo dyes and human health: A review. Journal of Environmental Science and Health, Part C 2016, 34, 233-261, https://doi.org/10.1080/10590501.2016.1236602.

37. Cerrón-Calle, G.A.; Aranda-Aguirre, A.J.; Luyo, C.; Garcia-Segura, S.; Alarcón, H. Photoelectrocatalytic decolorization of azo dyes with nano-composite oxide layers of $\mathrm{ZnO}$ nanorods decorated with $\mathrm{Ag}$ nanoparticles. Chemosphere 2019, 219, 296-304, https://doi.org/10.1016/j.chemosphere.2018.12.003.

38. Zafar, M.N.; Dar, Q.; Nawaz, F.; Zafar, M.N.; Iqbal, M.; Nazar, M.F. Effective adsorptive removal of azo dyes over spherical ZnO nanoparticles. Journal of Materials Research and Technology 2019, 8, 713-725, https://doi.org/10.1016/j.jmrt.2018.06.002.

39. Schmidt, C.; Berghahn, E.; Ilha, V.; Granada, C.E. Biodegradation potential of Citrobacter cultures for the removal of amaranth and congo red azo dyes. International Journal of Environmental Science and Technology 2019, 16, 6863-6872, https://doi.org/10.1007/s13762-019-02274-x. 
40. Arroyo Negrete, M.A.; Wrobel, K.; Yanez Barrientos, E.; Corrales Escobosa, A.R.; Acevedo Aguilar, F.J.; Wrobel, K. Determination of sulfonated azo dyes in chili powders by MALDI-TOF MS. Analytical and Bioanalytical Chemistry 2019, 411, 5833-5843, https://doi.org/10.1007/s00216-019-01965-1.

41. Rashidi, M.; Sajjadi, S.M.; Mousavi, H.Z. Kinetic analysis of azo dye decolorization during their acid-base equilibria: photocatalytic degradation of tartrazine and sunset yellow. Reaction Kinetics, Mechanisms and Catalysis 2019, 128, 555-570, https://doi.org/10.1007/s11144-019-01654-1.

42. Tiwari, S.; Deb, M.K. Modified silver nanoparticles-enhanced single drop microextraction of tartrazine in food samples coupled with diffuse reflectance Fourier transform infrared spectroscopic analysis. Analytical Methods 2019, 11, 3552-3562, https://doi.org/10.1039/C9AY00713J.

43. Li, J.; Liu, M.; Jiang, J.; Liu, B.; Tong, H.; Xu, Z.; Yang, C.; Qian, D. Morphology-controlled electrochemical sensing properties of CuS crystals for tartrazine and sunset yellow. Sensors and Actuators B: Chemical 2019, 288, 552-563, https://doi.org/10.1016/j.snb.2019.03.028.

44. Mirzajani, R.; Karimi, S. Ultrasonic assisted synthesis of magnetic Ni-Ag bimetallic nanoparticles supported on reduced graphene oxide for sonochemical simultaneous removal of sunset yellow and tartrazine dyes by response surface optimization: Application of derivative spectrophotometry. Ultrasonics Sonochemistry 2019, 50, 239-250, https://doi.org/10.1016/j.ultsonch.2018.09.022.

45. Bessegato, G.G.; Brugnera, M.F.; Zanoni, M.V.B. Electroanalytical sensing of dyes and colorants. Current Opinion in Electrochemistry 2019, 16, 134-142, https://doi.org/10.1016/j.coelec.2019.05.008.

46. Jadhav, S.A.; Garud, H.B.; Patil, A.H.; Patil, G.D.; Patil, C.R.; Dongale, T.D.; Patil, P.S. Recent advancements in silica nanoparticles based technologies for removal of dyes from water. Colloid and Interface Science Communications 2019, 30, 1-12, https://doi.org/10.1016/j.colcom.2019.100181.

47. Siddiqui, S.I.; Fatima, B.; Tara, N.; Rathi, G.; Chaudhry, S.A. 15 - Recent advances in remediation of synthetic dyes from wastewaters using sustainable and low-cost adsorbents. In: The Impact and Prospects of Green Chemistry for Textile Technology, Shahid ul, I., Butola, B.S., Eds.; Woodhead Publishing: 2019; pp. 471-507, https://doi.org/10.1016/B978-0-08-102491-1.00015-0.

48. Penagos-Llanos, J.; García-Beltrán, O.; Calderón, J.A.; Hurtado-Murillo, J.J.; Nagles, E.; Hurtado, J.J. Simultaneous determination of tartrazine, sunset yellow and allura red in foods using a new cobalt-decorated carbon paste electrode. Journal of Electroanalytical Chemistry 2019, 852, 1-26, https://doi.org/10.1016/j.jelechem.2019.113517.

49. Patel, B.K.; Sepay, N.; Mahapatra, A. Curious Results in the Prospective Binding Interactions of the Food Additive Tartrazine with $\quad \beta$-Lactoglobulin. Langmuir 2019, 35, 11579-11589, https://doi.org/10.1021/acs.langmuir.9b01242.

50. Wu, J.-H.; Lee, H.-L. Determination of sunset yellow and tartrazine in drinks using screen-printed carbon electrodes modified with reduced graphene oxide and NiBTC frameworks. Microchemical Journal 2020, 158, 1-6, https://doi.org/10.1016/j.microc.2020.105133. 